\title{
ИСТОКИ ФОРМИРОВАНИЯ ТЕОРИИ ЭКОНОМИЧЕСКИХ ЦИКЛОВ
}

\author{
(c) 2020 Афонасьев Максим Альбертович \\ аспирант \\ Самарский государственный экономический университет, Россия, Самара
}

В статье проводится исторический обзор теоретических взглядов и концепций, положивших начало возникновению и развитию теории экономических циклов. При этом рассматриваются предпосылки и источники возникновения подхода к выделению периодических колебаний в экономике. Помимо классических для экономической науки теорий рассмотрен ряд специфических взглядов на причины и природу экономических колебаний, таких как теории внешних факторов, психологические теории циклических колебаний. В результате анализа многообразных подходов автором сделан вывод о неоднозначности и сложности проблемы циклических изменений экономики и их роли в экономическом развитии.

Ключевые слова: экономические циклы, бизнес-циклы, колебания, экономическая динамика, кейнсианские теории.

\section{Введение}

Концепции экономических колебаний и образованные на их основе теории представляют собой целое отдельное поле научных исследований в рамках экономической науки. С тех пор, как во второй половине XIX в. наличие периодических колебаний экономики было доказано эмпирически, данный феномен привлекает внимание ученых с разными взглядами и подходами к объяснению природы и характера этих циклических изменений. В результате были сгенерирован целый ряд теорий, генезис которых происходит на протяжении дальнейшей истории развития экономической науки по наши дни.

Такой пристальный научный интерес и актуальность вопроса объясняется тесной связью феномена экономических колебаний с проблемами экономического развития и роста. На практике данная проблематика также находит отражение в разработке антициклической политики и управлении конъюнктурными колебаниями.

\section{Методы исследования}

Наша цель в рамках данной статьи - дать исторический обзор эволюции теорий экономических циклов с конца XIX века. По возможности, в исторической последовательности мы постараемся представить возникающие теории, чтобы дать представление о том, как они развивались и в каком направлении в определенные периоды времени.
Базовая и давно общепринятая идея заключается в том, что в целом, экономика не развивается с устойчивым трендом, а переживает случайные всплески активности и спады. Практически каждый экономист признает существование колебаний общего уровня экономической активности. Но идея о том, что вся экономика имеет регулярную циклическую структуру, то есть эти колебания повторяются с определенной периодичностью, была выдвинута только в конце XIX века.

Учеными делаются попытки классифицировать теории экономических циклов с той или иной позиции $[2,7]$. Это является непростой научной задачей в силу многообразности аспектов и взглядов на природу изучаемых колебаний. По этой же причине большую сложность представляет собой реализация идеи создания единой теории экономических циклов [2. В данном случае мы рассмотрим теории во временной последовательности их появления, приняв в качестве верхней границы периода кейнсианскую революцию.

Виды теорий на исторических этапах развития истоков исследования экономических колебаний

1. Теории внешних факторов или естественные теории

Первые исследователи экономических колебаний обосновывали циклы полностью внешними факторами.

Данные теории связывали экономические 
циклы с другими экзогенными циклическими явлениями, имеющими место в природе, такими как погода, на которую, в свою очередь, могли влиять астрономические явления. Теоретики утверждали, что природные явления, влияя на материальную и нематериальную сферу (например, урожай и настроения людей в обществе), в свою очередь, порождают наблюдаемые эконмические колебания.

Наиболее известными представителями этого вида теорий являются следующие.

Теория солнечных пятен Джевонса. Уильям Стэнли Джевонс (1835-1882) утверждал, что солнечные пятна, или интенсивная солнечная активность, возникающая периодически (примерно каждые 10-12 лет), вызывают колебания климата, поочередно порождая периоды засухи и наводнений. Эти периоды, в свою очередь, вызывают подъемы и спады в сельском хозяйстве, которые затем вызывают колебания общей экономической активности в связи с изменениями цен на сельскохозяйственную продукцию и влияния на торговые циклы $[7,11]$.

Работы Джевонса на эту тему были опубликованы в 1870-х годах. Можно предположить, что данная теория вполне имеет обоснование: для менее технологически развитых и аграрных экономик причинно-следственная связь может иметь большее влияние.

Позже Генри Л. Мур предложил теории, одна из которых опирается на погодные циклы (1914), а другая - на положение планеты Венера (1923) [7, 11]. В начале тридцатых годов (1932) Акерман, выдвинул предположение о связи более длительных экономических циклов с усиленными эффектами серии небольших сезонных циклов, обусловленных погодой [9].

Однако экономики индустриализирующихся стран XIX века демонстрировали другой тип регулярного циклического поведения, которое не могло быть напрямую связано с природными факторами. Эти колебания стали известны как торговые или деловые циклы (бизнес-циклы).

2. Докейнсианские теории циклических колебаний

Первые попытки объяснить циклические движения не имели прочных экономических обоснований, главным образом потому, что они основывались на теориях внешних факторов. Однако последующий период развития теорий экономических циклов заключался в распространении исследований, направленных на ин- терпретацию циклических колебаний в свете экономических теорий.

Наряду с большим разнообразием исследований, направленных на выявление, измерение и, по возможности, прогнозирование циклических движений период конца XIX и начала XX веков характеризовался большим количеством исследований и публикаций о причинах, определяющих деловой (экономический) цикл. Данные исследования в основном были направлены на выявление причин циклических колебаний и их объяснение в рамках макроэкономической теории [11].

Следует отметить, что в этот исторический период впервые возникло разделение между детерминистскими, или полностью эндогенными, теориями циклических флуктуаций (согласно которым, циклы порождаются только внутренними причинами экономической системы) и стохастическими теориями с некоторой степенью экзогенности. Даже на сегодняшний день это различие вызывает научные дебаты.

Наглядным примером докейнсианских теорий можно назвать экономические циклы недостаточного потребления или теорию недопотребления. Этот подход получил большое признание со стороны ряда экономистов. Они утверждали, что причиной верхней поворотной точки цикла является снижение способности экономики продолжать потреблять то, что она производит во время фазы расширения.

Недостаточное потребление - это не просто теория, а система, в рамках которой было разработано несколько теорий, основанных на этой концепции

Bсе эти теории, по существу, развивались в противовес классическому экономическому взгляду [11].

Взгляд Маркса на нестабильность имеет сильные коннотации недопотребления. Его анализ привел его к предсказанию, что революция наступит сначала в самой зрелой капиталистической стране [5]. Теория совокупного спроса, разработанная Кейнсом, также основана на некоторых аспектах теорий недостаточного потребления. Тем не менее, с кейнсианской точки зрения, ситуация недостаточного потребления не обязательно приводит к экономическому кризису, поскольку в совокупности согласно теории спроса, недостаточное потребление может быть уравновешено другими компонентами, такими как рост, накопление основного капитала и государственное потребление [1, 3]. 
Сберегательно-инвестиционные теории. Эти теории рассматривают влияние, которое существование эластичной денежной системы может оказать на экономическое равновесие. Эти теории отличаются от классических главным образом тем, как в них рассматриваются отношения между банковской системой и инвестициями.

Рыночный закон и предположение гибкой заработной платы и цен привели к выводу, что полная занятость обеспечивает долгосрочное естественное равновесие для экономики. Колебания деловой активности считались незначительными самокорректирующимися явлениями.

При этом циклическое расширение денежной массы вызвано стремлением банковского сектора к прибыли. Шведский экономист Викселл $(1898,1936)$ ввел различие между естественными и рыночными процентными ставками. При естественной процентной ставке предложение сбережений будет равняться спросу на заемные средства, который определяется тем, что предприниматели хотят инвестировать. Рыночная процентная ставка, приравненная к спросу на средства в банке-завышенное предложение кредитов. Следовательно, воздействие функционирования банковской системы должно было привести к тому, что рыночная процентная ставка окажется ниже естественной. Только когда обе ставки одинаковы, экономика достигает равновесия. Расхождение между двумя процентными ставками порождает циклические колебания, обусловленные к тому, что инвестиционный спрос не сбалансирован адекватной доступностью сбережений.

Теория циклических колебаний реальной экономики Робертсона

Теория Робертсона (Robertson, 1915, 1948) предполагает, что циклические флуктуации в основном или даже исключительно приписываются факторам реального сектора экономики. Инновации могут создавать скачки в экономическом росте и подталкивать предпринимателей к запуску новых инвестиционных проектов с целью получения прибыли от новых технологий. Так как инвестиционные планы предпринимателей являются неизвестным фактором, это приведет к ситуации чрезмерных инвестиций, что выведет затем экономику из ее равновесного положения, По мнению Робертсона, экономические колебания являются неизбежной составляющей экономического роста, связанной с технологическим развитием и инновациями.
При этом активная денежно-кредитная политика не способна сыграть антициклическую роль и, скорее, усилит последствия кризиса, чем смягчит их.

Теории пост-периода Великой депрессии

После Великой депрессии 1929 года возник большой импульс в изучении природы, причин и последствий циклических колебаний. Несмотря на то, что подобные исследования не привели к единому теоретическому взгляду, они характеризуются общим фактором - влиянием последствий Великой депрессии на взгляды экономистов.

Теория Фриша. Впервые Фриш (Frisch, 1933) выдвинул гипотезу о том, что циклические движения порождаются накоплением со временем экзогенных шоков, которые стремятся вывести экономику из равновесного положения. Эта теория в основном базировалась на работах Е. Слуцкого, которого можно считать одним из пионеров современного анализа временных рядов [6].

Общая идея, на которой основана данная теория, заключается в том, что «импульсы» или «шоки», которые приводят к экономическому циклу, имеют стохастический характер и поэтому являются довольно нерегулярными; механизм распространения преобразует последовательность таких импульсов в последовательность циклов, длина которых зависит от параметров этого механизма, но амплитуда которых зависит от силы импульсов. Механизм распространения в основном основан на принципе ускорения, связывающем уровень заказов и производство инвестиционных товаров с изменением производства потребительских товаров [11].

Теория Фриша объединяет стохастическую составляющую, представленную экзогенными импульсами, влияющими на экономическое равновесие, с более детерминированным методом распространения, порождающим циклы. Взаимодействие между стохастическими и детерминированными факторами может возникнуть сложная ситуация, которая может порождать циклы различной периодичности, не обязательно синхронизированные между собой.

Инновационная теория Шумпетера

Мысль Шумпетера была направлена на то, чтобы лучше определить различные фазы циклических движений и основные факторы, влияющие на каждую из них [8]. Взгляд Шумпетера на циклические движения является лишь частью более общей экономической теории эко- 
номического развития капиталистической системы. В нормальной ситуации, без каких-либо существенных изменений с технологической или инновационной точки зрения, экономика должна находиться в стабильном равновесии, таком как равновесие Вальраса. Эта ситуация равновесия также может быть динамичной во времени но с фиксированными параметрами, которые не допускают каких-либо изменений во взаимоотношениях между различными агентами и рынками.

Предприниматели являются движущими силами капиталистического развития. Отклонение от равновесия имеет микроэкономическое происхождение. Оно порождается потребностью предпринимателей в инновациях и предоставлением кредитов для финансирования таких инноваций банками. Фаза расширения порождается инновациями, которые мобилизуют ресурсы. Во время этого расширения ресурсы перераспределяется в пользу предпринимателей-новаторов. Когда этот процесс завершится, на рынок поступят новые продукты, и равновесие изменится.

Возврат к равновесию или к новому равновесию достигается затем через фазу спада, когда конкурирующие виды деятельности устраняются. Описанный процесс можно рассматривать как простейшую схему циклических колебаний как чередование фаз процветания и спада.

В такие периоды равновесие также будет развиваться по тренду, который эндогенно определяется последовательность нововведений. Это можно рассматривать как первый пример экономического устойчивого состояния, вокруг которого колеблется экономика. Простой контур циклических движений может легко стать более сложным из-за вторичных эффектов, вызванных инновациями, которые могут породить вторичный цикл. В этом контексте вполне возможно, что спекулятивные пузыри возникают с риском серьезных депрессий.

По мнению Шумпетера, полный цикл характеризуется четырьмя четко различимыми фазами:

- процветание,

- спад,

- депрессия

- выздоровление [8].

Шумпетер расширил предположения об одном цикле, характеризующем экономические колебания. Исходя из множественности и неоднородности инноваций, он выдвинул гипотезу о системном подходе к циклическим движениям, основанным на различных циклах, каждый из которых имеет отличительные характеристики с точки зрения длины, движущих сил и т.д. Таким образом, он предлагал три циклические схемы:

- короткую: 3-5-летний цикл инвентаризации (согласно Дж. Китчину);

- среднюю: 7-11-летний цикл инвестиций в основной капитал (согласно Джуглару);

- длинную: 45-60-летний технологический цикл (по Кондратьеву).

Строительный цикл или цикл Кузнеца

Русский экономист С.Кузнец, получивший образование в Соединенных Штатах Америки, специализировался на изучении национального дохода и формировании капитала. Он дал характеристику экономическому циклу длительностью от 16,5 до 18 лет.

Этот цикл является как долгосрочным, так и краткосрочным. Краткосрочные колебания связаны с кредитными рынками. Долгосрочная волна - это, прежде всего, функция демографии.

Базовая схема для цикла Кузнеца заключается в следующем. Во время экономического благополучия спрос на рабочую силу возрастает, что оказывает повышательное влияние на заработную плату. В свою очередь, улучшение экономических условий приводит к увеличению числа новых семейных образований, что порождает спрос на новые жилые объекты.

Строительный цикл был построен для понимания фаз цикла недвижимости, что очень важно для определения сроков инвестирования. Строительный цикл делится на четыре фазы:

- развитие,

- перестройка

- регулировка

- приобретение.

Фазы строительного цикла для различения конкретных фаз контролируются циклом спроса и предложения, представленным продажами жилья (сторона спроса на рынке) и началом строительства жилья (сторона предложения на рынке).

Развитие заключается в том, что спрос растет, и за этим следует увеличение объемов строительства жилья. Эта фаза характеризуется низким уровнем вакантных площадей и ростом арендной платы. Он достигает зрелости примерно через 3-5 лет. Сигналом этого переломного момента является агрессивное повышение цен на землю. 
Перестройка - это фаза, когда жилье начинает стабильно опережать продажи жилья.

Корректировка - это фаза, когда строительная отрасль реагирует на снижение спроса и сворачивает строительство жилья.

Приобретение - это фаза цикла, когда строительство продолжает снижаться, в то время как продажи жилья устойчивы. Строительная деятельность еще больше сокращается, хотя уровень вакантных площадей достиг своего пика, а концессии на аренду жилья прекратились.

\section{Циклы Кондратьева.}

Российский экономист Николай Кондратьев в рамках своих исследований привел несколько эмпирических характеристик своей длинной волны - цикл экономической активности, длящийся примерно 54 года [4]. Данный цикл показывает повторяющиеся периоды все возрастающего экономического роста и спада. Кондратьев заметил, что из состояния депрессии рыночная экономика порождает новый цикл экспансии, в основном основанный на новой технологии. При этом, новая технология была разработана лишь частично на поздних стадиях предыдущего цикла.

Такое описание демонстрирует способность свободных эконмических субъектов к выживанию в рыночной среде (капитализме). Исследование Кондратьева, в сущности, показало присущий капитализму механизм и способность к самокоррекции.

Данные наблюдения привели к теоретическому объяснению длинной волны Дж.Шумпетером и другими учеными, которые разработали инновационную теорию длинной волны.

Развитие идей системы Кондратьева выявило ее дополнительную интересную способность - предсказывать будущее развитие экономики, общий уровень цен, рынок облигаций и фондовый рынок. По мнению Шумпетера, система Кондратьева представляет собой наиболее важный прогнозный инструмент.

Тем не менее, возможность идентифицировать цикл Кондратьева и затем подтвердить предположения, лежащие в основе его существования, все еще остается открытой проблемой без решения.

\section{Заключение}

Проведенный нами анализ возникновения предпосылок и развития теорий экономических циклов дает представление о сложности и комплексности вопроса изучения экономического роста в целом. Появление теорий определенных видов на протяжении рассмотренного периода демонстрирует тесную взаимосвязь с характером развития экономики и общества в целом.

Среди множества подходов разных специалистов и ученых стоит отметить вклад Й.Шумпетера в теоретическое определение и объяснение экономических циклов. Его исследования являются, без сомнения, наиболее полной и системной работой периода, предшествовавшего Второй мировой войне. Данные исследования сохраняют актуальность и по сей день, оказывая влияние на многие теории циклических движений.

Следующим важным выводом по результатам обзора мнений и теорий можно обозначить следующее. Циклические колебания не обязательно имеют негативные последствия для экономического роста. Они порождаются инновациями - основным двигателем экономического развития. Колебания перемещают экономику из равновесного положения в следующее, которое, вероятно, лучше предыдущего, благодаря тому, что инновации вывели экономику на новый уровень.

Однако, как показывает обзор современных научных позиций и стремлений государственной антициклической политики, такой подход зачастую находится в противоречии с большинством работ современных авторов, дающих негативную интерпретацию экономическим колебаниям. Вместе с тем, история демонстрирует неизбежность колебаний в любых экономических системах и наличие закономерностей в их происхождении. Это обстоятельство требует дальнейшего развития и проработки теорий экономических циклов с учетом предшествующего научного опыта, а также новых явлений и вызовов для современного общества.

\section{Библиографический список}

1. Баликоев В. З. Общая экономическая теория: учеб. - 11 изд.- М.: Издательство «Омега-Л», 2008. - 732 с.

2. Зикунова И.В.Генезис и развитие теорий делового цикла в экономической науке // Вестник ЛГУ им. А. С. Пушкина. 2009. Т. 6. № 3. С. 5-24.

3. Кейнс, Дж. М. Общая теория процента, занятости и денег.- М.: Прогресс, 1978. - 494 с 
4. ондратьев, Н.Д. Большие циклы конъюнктуры и теория предвидения. Избранные труды / Н.Д. Кондратьев; Международный фонд Н.Д, Кондратьева и др.; Ред. колл.: Абалкин Л. И. (пред.) и др.; сост. Яковец Ю. В. М.: ЗАО «Издательство «Экономика».-2002.-767 с.

5. Маркс К. Капитал. Критика политической экономии. Процесс производства капитала / под ред. Ф. Энгельса. Т. 1. Кн. 1.- М.: Политиздат, 1978.- 907 с.

6. Слуцкий Е. Е. Экономические и статистические произведения. Избранное - М.: Эксмо. 2010. - 1152 с.

7. Тупиченко В. А., Кривцова М. К. Ключевые теории экономического цикла // Финансовая аналитика: проблемы и решения. 2014. № 3 (189). С. 2-12.

8. Шумпетер Й. А. Теория экономического развития / Й.А.Шумпетер.- М.: Директмедиа Паблишинг, 2008.$401 \mathrm{c}$.

9. Åkerman, J. Economic progress and economic crisis. Macmillan and Co.Ltd, London. 1932. - 190 p.

10. Allgoewer, E. Underconsumption theories and Keynesian economics. Interpretations of the Great Depression / University of St. Gallen Department of Economics working paper series 2002. 2002-14, Department of Economics, University of St. Gallen. - URL: https://ideas.repec.org/p/usg/dp2002/2002-14.html.

11. Fayole J., The study of cycles and economic analysis in the history of economic thought, Monographs of official statistics, Papers and proceedings of the colloquium on the history of business-cycle analysis/ Luxembourg: Office for Official Publications of the European Communities, 2003. - 208 p. 